Supporting Information

for

\title{
Monolithic Membranes with Designable Pore Geometries and Sizes via Retarded Evaporation of Block Copolymer Supramolecules
}

\author{
Leiming Guo and Yong Wang
}

State Key Laboratory of Materials-Oriented Chemical Engineering, College of Chemical Engineering, Nanjing Tech University, Nanjing 210009, Jiangsu, China

${ }^{*}$ Corresponding authors.

E-mail: yongwang@njtech.edu.cn

Tel: 0086-25-8317 2247

Fax: 0086-25-8317 2292 
Table S1. The preparation conditions of aligned supramolecular films with different morphologies and thicknesses

\begin{tabular}{|c|c|c|c|c|c|c|}
\hline Morphology & $f_{P 4 V P(P D P)}{ }^{a}$ & $\begin{array}{l}\text { Thickness } \\
\text { of the } \\
\text { dried } \\
\text { film/ } \mu \mathrm{m}\end{array}$ & $\begin{array}{l}\text { Concentration } \\
\text { of the } \\
\text { supramolecular } \\
\text { solution/ wt \% }\end{array}$ & $\begin{array}{l}\text { Volume of the } \\
\text { supramolecular } \\
\text { solution/ } \mu \mathrm{L}\end{array}$ & $\begin{array}{c}\text { Volume of } \\
\text { additional } \\
\text { chloroform/ } \\
\mu \mathrm{L}\end{array}$ & $\begin{array}{l}\text { Evaporation } \\
\text { Duration/ } \mathrm{h}\end{array}$ \\
\hline $\begin{array}{l}\text { Disordered } \\
\text { structures }\end{array}$ & $25 \%$ & 6 & 0.5 & 150 & 2400 & 60 \\
\hline \multirow[t]{3}{*}{ cylinders } & $28 \%$ & 6 & 0.52 & 150 & 2400 & 60 \\
\hline & & 0.25 & 0.11 & 50 & 300 & 6 \\
\hline & & 0.6 & 0.53 & 30 & 500 & 12 \\
\hline \multirow{5}{*}{$\begin{array}{l}\text { Perpendicular } \\
\text { cylinders }\end{array}$} & & 2 & 0.53 & 100 & 1600 & 36 \\
\hline & $30 \%$ & 3.5 & 0.53 & 120 & 2000 & 46 \\
\hline & & 6 & 0.53 & 150 & 2400 & 60 \\
\hline & & 13 & 1.07 & 150 & 3600 & 96 \\
\hline & & 65 & 1.07 & $1000^{b}$ & 800 & one week \\
\hline Gyroids & $35 \%$ & 7 & 0.63 & 150 & 2400 & 60 \\
\hline Lamellae & $50 \%$ & 6 & 0.75 & 150 & 2400 & 60 \\
\hline $\begin{array}{l}\text { Reversed } \\
\text { cylinders }\end{array}$ & $70 \%$ & 6 & 1.25 & 150 & 2400 & 60 \\
\hline
\end{tabular}

a $f_{\mathrm{P} 4 \mathrm{VP}(\mathrm{PDP})}$ indicates the mass fraction of $\mathrm{P} 4 \mathrm{VP}(\mathrm{PDP})$ in the supramolecular system.

b For the alignment of bulk film with the thickness of $65 \mu \mathrm{m}$, a large volume of the supramolecular solution has to be used, which cannot be held on a flat silicon substrate. Alternatively, we used a small PTFE vial with the diameter of $1.5 \mathrm{~cm}$ to accommodate the solution. $1000 \mu \mathrm{L}$ of the supramolecular solution with the concentration of 1.07 wt $\%$ was filled into the small vial previously positioned in the PTFE container for retarded evaporation together with $800 \mu \mathrm{L}$ of additional chloroform. The container was covered with its lid and the evaporation last for approximately one week. 
a)
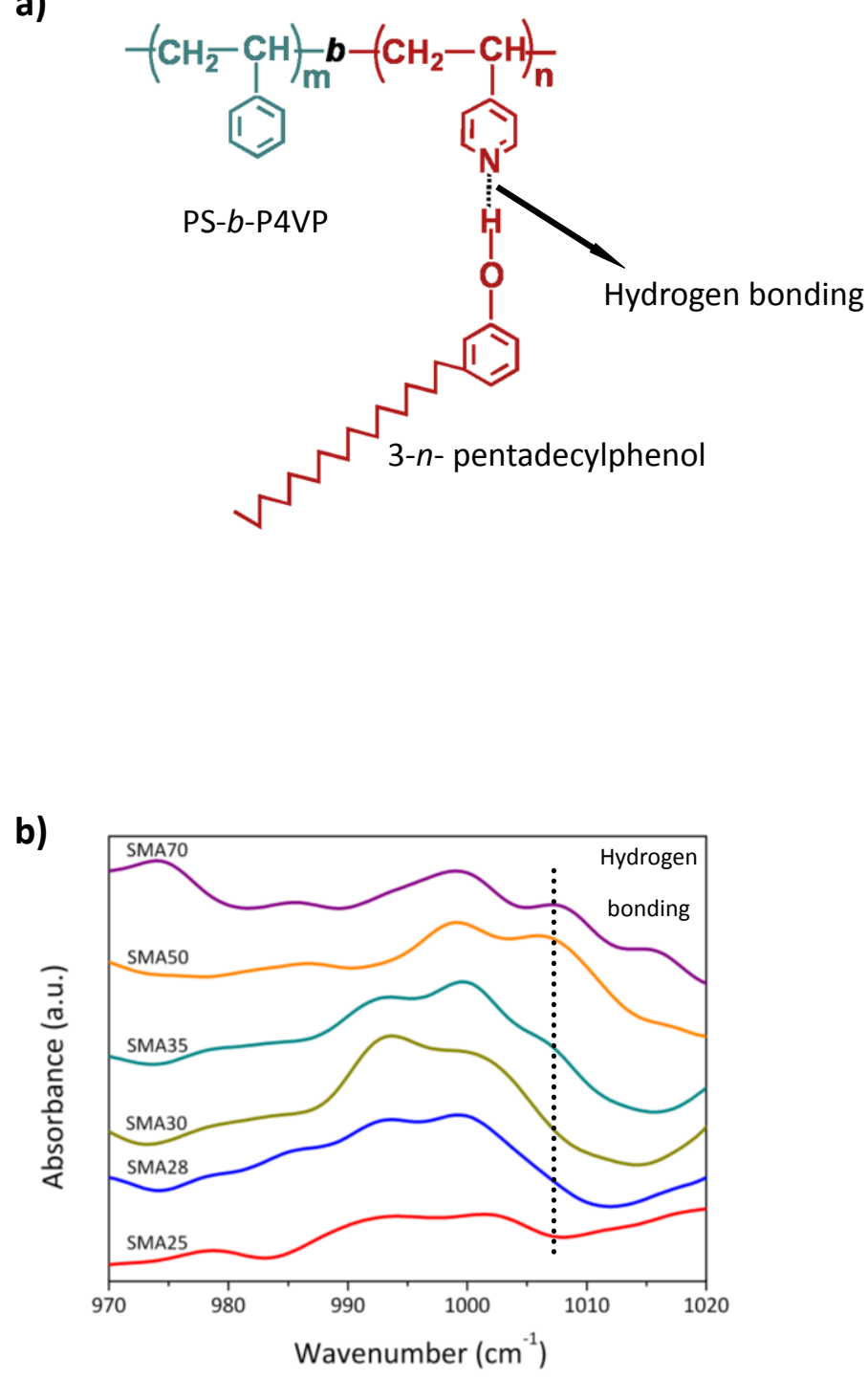

Figure S1. (a) Schematic representation of the PS- $b$-P4VP(PDP) supramolecular system; (b) FTIR spectra of supramolecular films with different

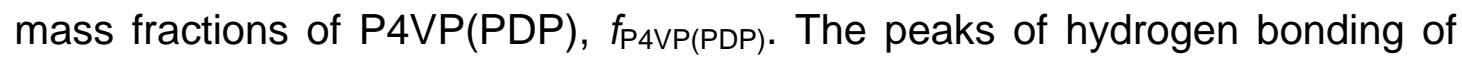
SMA28 and SMA30 films are undetectable because of the small accounts of PDP existing in the supramolecular systems (e. g. SMA28=( $\left.\left.f_{\mathrm{P} 4 \mathrm{VP}(\mathrm{PDP})}=28 \%\right)\right)$. 


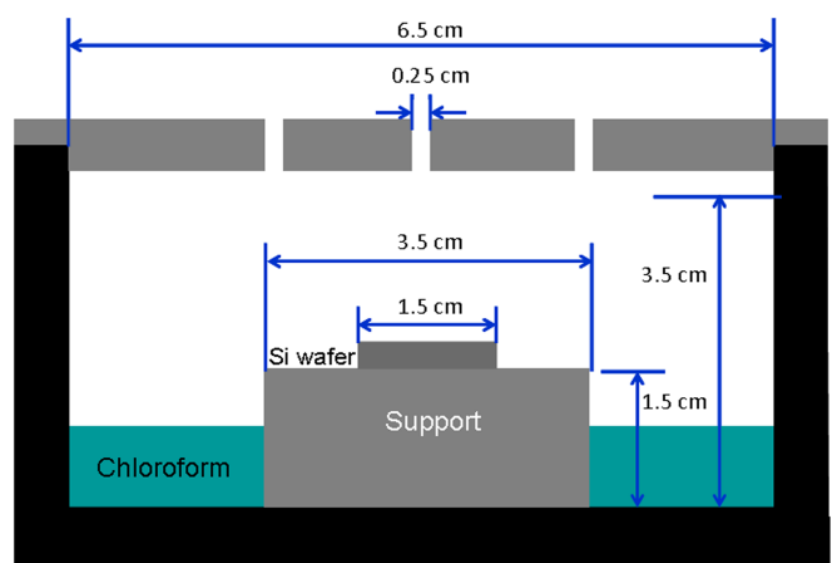

Figure S2. Schematic illustration of the PTFE container used for the retarded evaporation of the PS-b-P4VP(PDP) solution. The supramolecular solution was cast on the Si wafer placed on the support in the container, and additional chloroform was filled into the container without direct contact to the supramolecular solution. The container was immediately sealed with its lid and three holes with the diameter of $2.5 \mathrm{~mm}$ drilled on the lid allowed the retarded evaporation of chloroform.

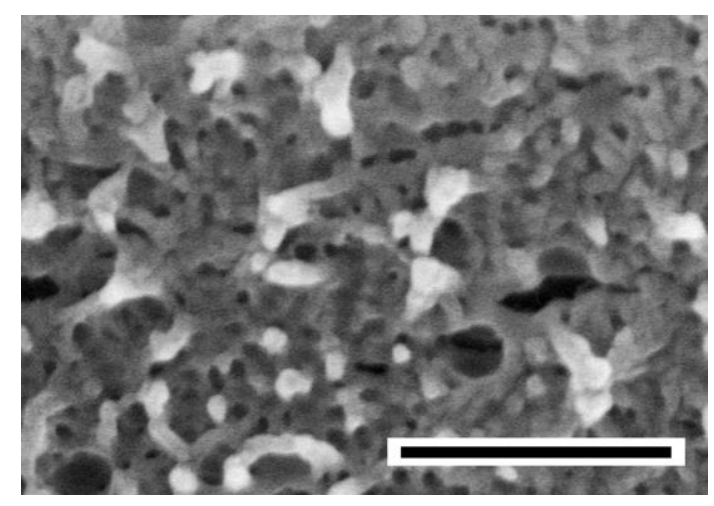

Figure S3. The SEM cross section of the neat PS- $b$-P4VP monoliths obtained by retarded evaporation after ethanol swelling at $50{ }^{\circ} \mathrm{C}$ for $12 \mathrm{~h}$. The scale bar corresponds to $500 \mathrm{~nm}$. 

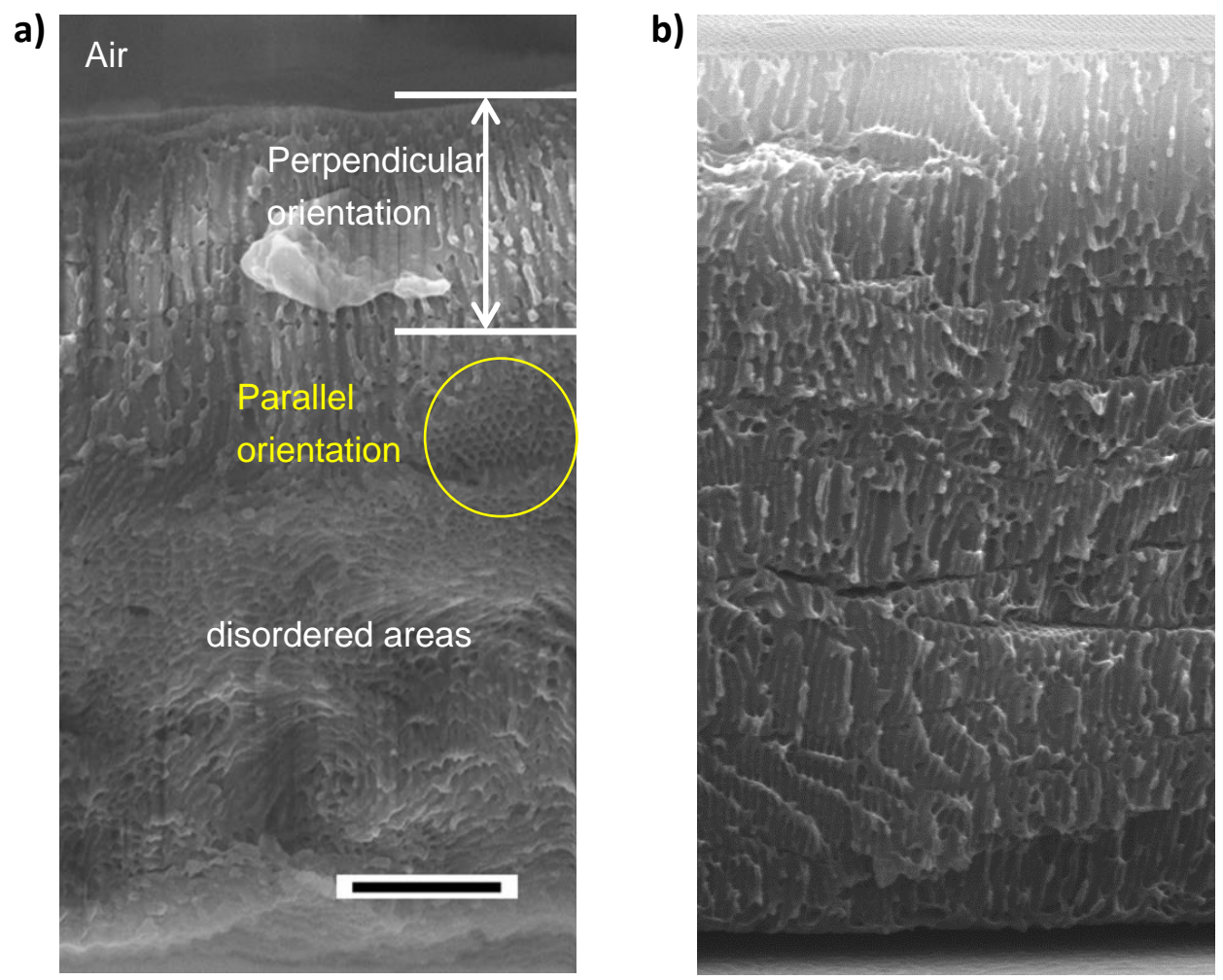

Figure S4. The cross-sectional SEM images of the supramolecular monoliths with $f_{\mathrm{P} 4 \mathrm{VP}(\mathrm{PDP})}=30 \%$ obtained at a evaporation duration of $26 \mathrm{~h}(\mathrm{a})$ and $60 \mathrm{~h}(\mathrm{~b})$ followed by ethanol washing at room temperature for $12 \mathrm{~h}$. The images have the same magnification and the scale bar is shown in (a) and corresponds to 1 $\mu \mathrm{m}$. 


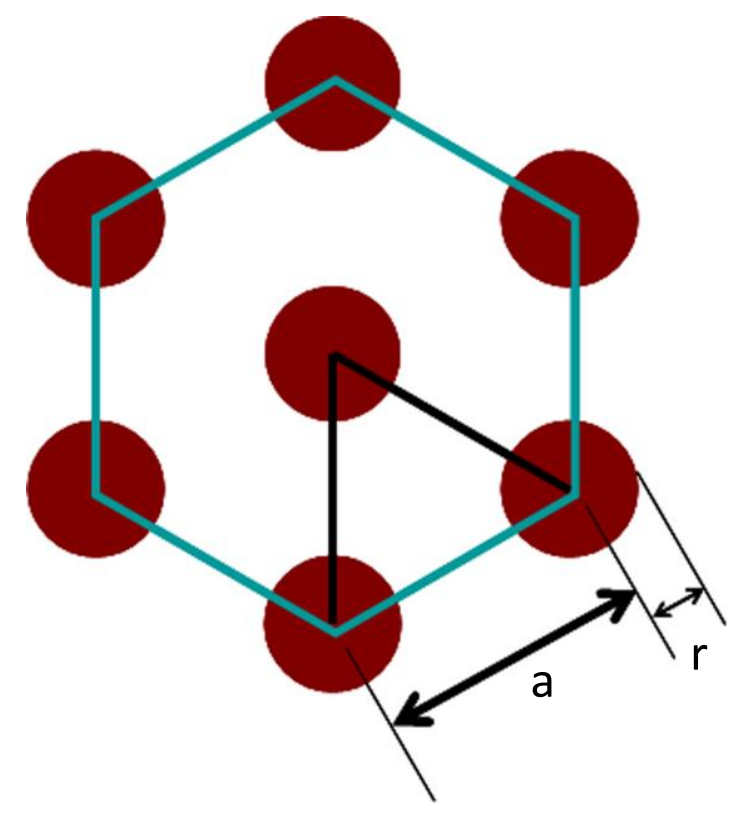

Figure S5. Illustration of the calculation of the surface porosity of membranes with hexagonally patterned pores. Surface porosity, $\varepsilon=\frac{3 \pi \times r^{2}}{6 \times\left(\frac{\sqrt{3}}{4} a^{2}\right)}=\frac{2 \pi \times r^{2}}{\sqrt{3} a^{2}}$, where $r$ is the pore radii, and $a$ is the center-to-center spacing between adjacent pores.

a)

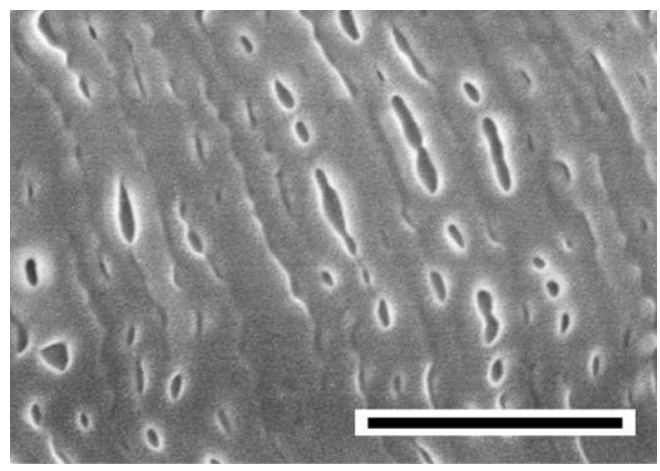

b)

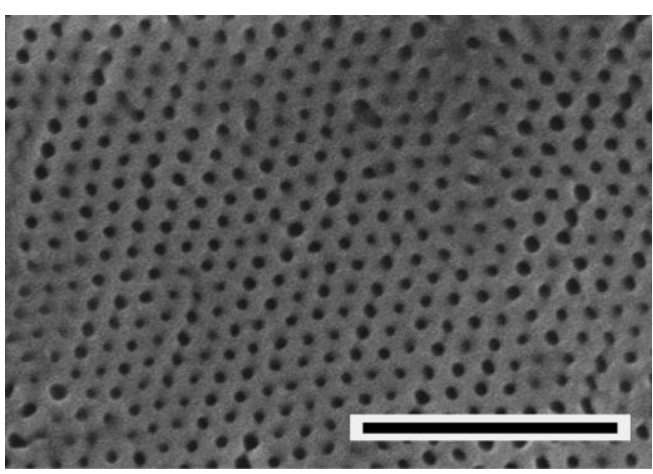

Figure S6. The SEM images of the bottom surface of 2 - $\mu \mathrm{m}$-thick perpendicularly aligned supramolecular films with $f_{\mathrm{P} 4 \mathrm{VP}(\mathrm{PDP})}=30 \%$ coated on bare Si substrates with a native oxide layer (a) and Si substrates grafted with PS-OH (b) after ethanol soaking at $55{ }^{\circ} \mathrm{C}$ for $1 \mathrm{~h}$, respectively. The scale bars correspond to $500 \mathrm{~nm}$. 
a)

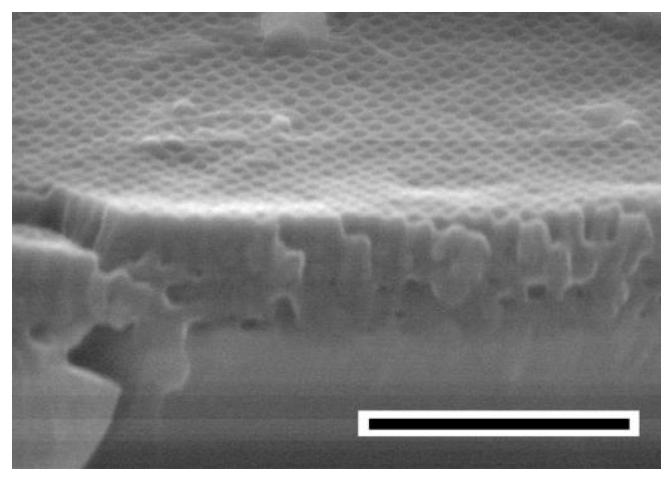

c)

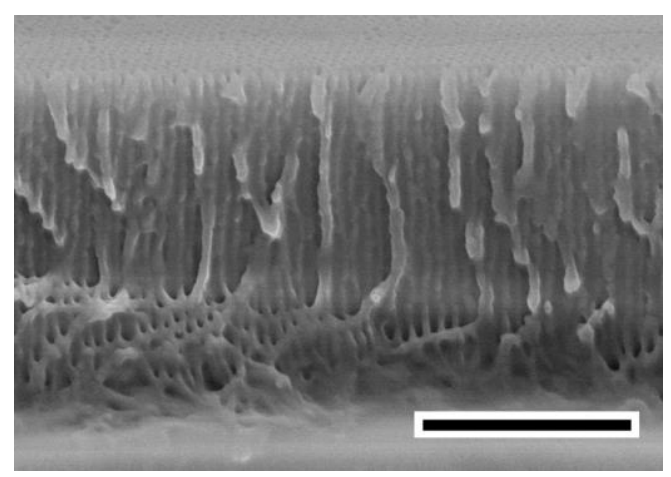

e)

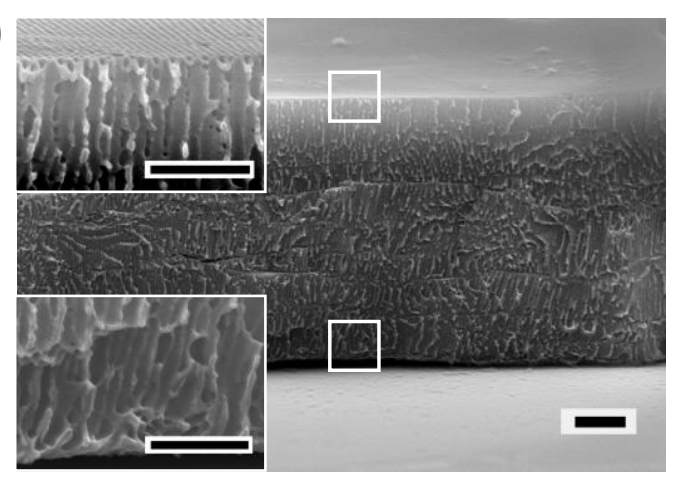

b)

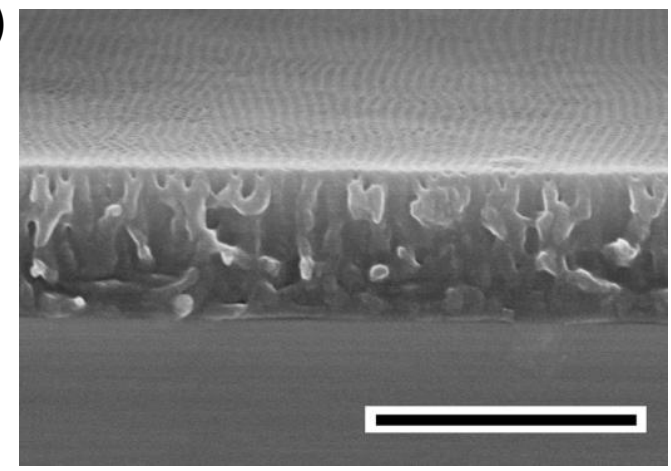

d)

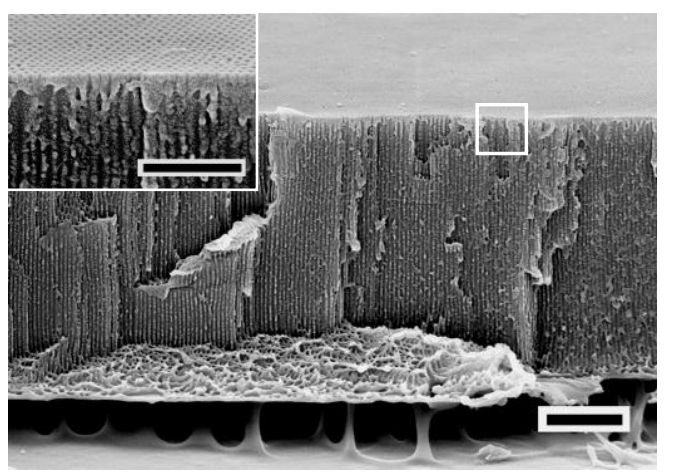

f)

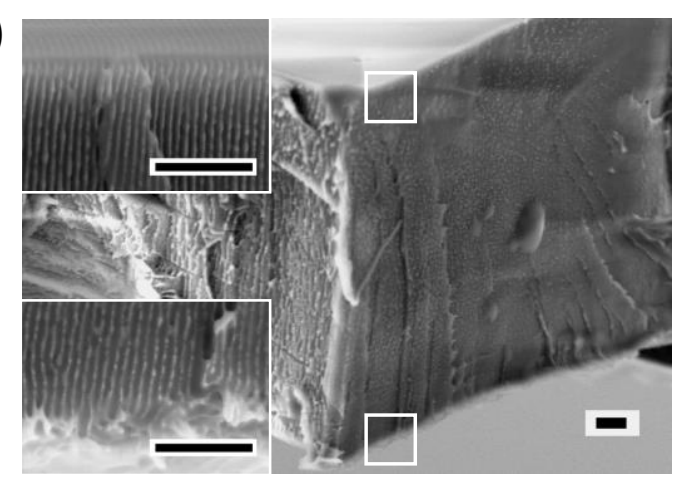

Figure S7. Cross-sectional SEM images of membranes prepared from perpendicularly aligned supramolecules at $f_{\mathrm{P} 4 \mathrm{VP}(\mathrm{PDP})}=30 \%$ with the thickness of $250 \mathrm{~nm}(\mathrm{a}), 600 \mathrm{~nm}(\mathrm{~b}), 2 \mu \mathrm{m}$ (c), $3.5 \mu \mathrm{m}$ (d), $6 \mu \mathrm{m}$ (e), and $13 \mu \mathrm{m}(\mathrm{f})$. The scale bars in all panels correspond to $1 \mu \mathrm{m}$. The insets in each panel are the magnifications of the corresponding boxed areas and the scale bars in all insets correspond to $500 \mathrm{~nm}$. 

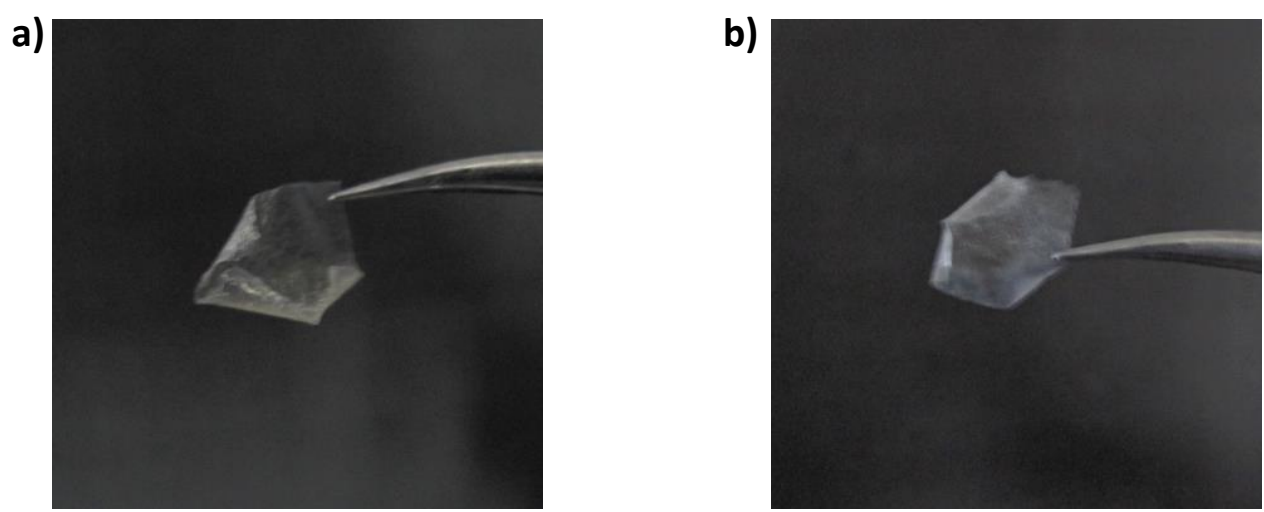

Figure S8. The photograph of the $13-\mu \mathrm{m}$-thick perpendicularly aligned supramolecular monolith with $f_{\mathrm{P} 4 \mathrm{VP}(\mathrm{PDP})}=30 \%$ before (a) and after (b) the removal of PDP by ethanol treatment at room temperature for $12 \mathrm{~h}$.

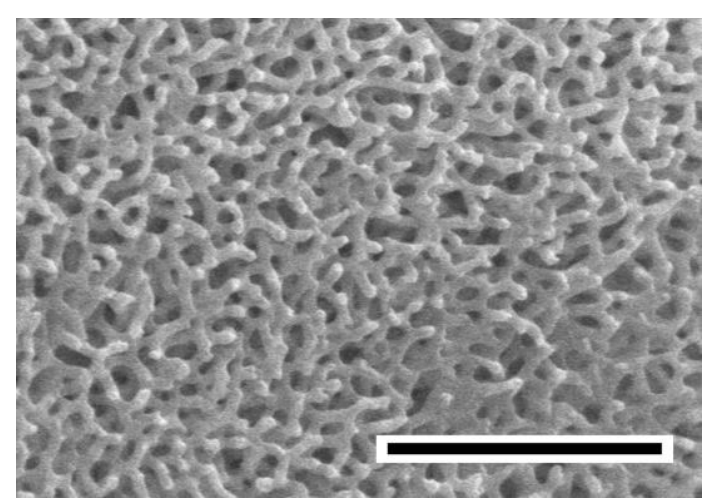

Figure S9. The SEM image of the collapsed structure of the supramolecular monolith in the morphology of gyroids subjected to ethanol swelling at $70^{\circ} \mathrm{C}$ for $12 \mathrm{~h}$. The scale bar corresponds to $1 \mu \mathrm{m}$. 